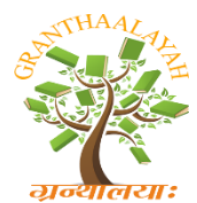

\author{
INTERNATIONAL JOURNAL OF RE
GRANTHAALAYAH \\ A knowledge Repository
}

Social

\title{
EXPLORING GENDER REPRESENTATION: PATRIARCHAL PERPECTIVES FROM EFL SECONDARY SCHOOL TEXTBOOKS IN INDONESIA
}

\author{
Ive Emaliana *1, Arcci Tusita ${ }^{2}$ \\ ${ }^{* 1,2}$ Universitas Brawijaya, Indonesia
}

\begin{abstract}
This paper seeks to investigate whether the Indonesian government's attempt to promote a genderequal society in recent decades and improve gender awareness are reflected in patterns of gender representation in EFL textbooks in secondary schools. The study made an analysis of four compulsory textbooks published in 2016 with corpus linguistic tools (e.g. pronouns, occupation, amount of talk) and how gender is represented in the visuals (or illustrations) through conducting frequency counts of the occurrence of male and female characters and the spheres of activities they engaged, to investigate the ration of female-to-male appearances, the extent of use of genderneutral, and gender-marked constructions, common address titles for reference, and order of appearance of women and men. The findings show that there is a need for evaluation of the existing language textbooks in secondary schools, with the aim of promoting a more gender-balanced learning material. Moreover, the classroom teachers raise the need for the promotion of initial as well as in-service training for teachers on issues of 'gender stereotypes', 'language sexism' and 'gender-mainstreaming policies'.
\end{abstract}

Keywords: EFL Textbook; Gender Awareness; Gender Representation.

Cite This Article: Ive Emaliana, and Arcci Tusita. (2019). "EXPLORING GENDER REPRESENTATION: PATRIARCHAL PERPECTIVES FROM EFL SECONDARY SCHOOL TEXTBOOKS IN INDONESIA.” International Journal of Research - Granthaalayah, 7(11), 146-153. https://doi.org/10.29121/granthaalayah.v7.i11.2020.345.

\section{Introduction}

Gender inequality that exists in many countries is one of many challenges that the world faces, albeit the governments of these countries have tried to employ various innovational elucidations to reform this issue. Gender is socially constructed under the influences of mass media, peers, schools, parents to make individual behave in particular ways that the communities expect he/she should. Gebregeorgis (2016) explicates gender as relationships and roles that is selected a priori by the society for both men and women, and it is considered as influential cultural and social values, traditions, and customs, which is changing over time and place. Gender, is socially 
established throughout human interaction and interpretation rather than biologically decided (Lee, 2014), creates differences between the sexes, and its interpretation often unfavorable to women (Kochuthara, 2011). In other words, gender inequality and bias are still present in many societies, especially in developing countries and in the Middle East (Al-Qatawneh \& Al-Rawashdeh, 2019; Gebregeorgis, 2016; Barton \& Sakwa, 2012; Yang, 2011). In Indonesia, the government had implemented various measures aimed at gender development, and to empower both male and female members of society through best practices and processes to ensure that gender balance target is achieved. One of the policies is Indonesian Republic Ministry of Education and Culture No. 81 A Year 2013 states that educational curriculum is directed towards development of equitable attitudes and behaviors focusing in gender equality.

Through educational materials, manifestations of gender norms can be perceived. Textbooks as educational materials become prominent classroom instruction and lesson planning devices to transfer knowledge as well as cultural norms. Students as in secondary schools are often bound to learn from and accept information presented in textbooks which are shaped by their authors' positions and expectations about the target audience (Apple, 2004). Textbooks also comprise hidden curriculum (Chu, 2018) that is not openly taught but learned by students through transfers of dominant power structures and cultural norms immersed in the texts (Eisner, 2002). Therefore, textbooks can be used to shape identities and mobilize citizens (Chu, 2018), such as English. In Indonesia, notwithstanding the enhancing urgency on student-centered learning, English textbooks are still inevitable instructional materials, and teachers allocate majority of class time in teaching textbooks. As English language consists words and phrases which demonstrate prejudice against particular gender group, these gender biases may be conveyed to students through textbooks in the forms of linguistics sexism. Pauwels (1998) states that English language has features that background or degrade women, including asymmetric expressions and default presentation of male gender as the norm. Besides, Porreca (1984), Pauwels (1998), and Mineshima (2008) add that exclusion of female and gender stereotyping are other common evidence of gender inequality found in educational materials. Accordingly, as English textbooks are significant source of information in Indonesian students' schooling experiences concerning what is taught in the classroom, it is indispensable to reveal hidden curriculum relating to gender construction in English textbooks in secondary schools, for any biases conveyed to the students may have a detrimental effects on their personal as well as cognitive development.

Extensive studies have been conducted about gender representation in the school textbooks content, especially EFL ones. Prior studies of Indonesian textbooks revealed that the unequal gender representations were derived from representation of visual images from the textbooks only (Elmiana, 2019) only. Through content analysis of social studies textbook representation of gender equality is not new in the literature (Al-Qatawneh \& Al-Rawashdeh, 2019; Lee, 2014; Barton \& Sakwa, 2012), little research has been conducted on both linguistics features and visual content (illustrations) of textbooks. The purpose of this study is comparing how women and men are represented in Indonesian EFL textbooks for secondary school students. The current study is regarded as significant for two reasons. Firstly, the Indonesian government has put more emphasis on English learning in recent years in order to increase international competitiveness. English has become the compulsory foreign language taught in secondary schools. While English language is considered as non sexist language, if students learn in schools authoritative textbooks which contain equal gender illustration and non-sexist language that use everyday, stereotypical thinking 
and beliefs will never be reinforced and sustained. Secondly, although Indonesian women were guaranteed equality in the constitution, it has been argued that there is a gap between reality and the ideals of law for gender equality. Given that school education is a catalyst for change, if gender equality is successfully established in schools, in the future, the move upon a gender equality society may face fewer problems. The present enquiry on Indonesian EFL textbooks, published after the incorporation of the stipulation on gender equality of the 2013 Education curriculum which emphasizes on gender equality, provide educators and the government information on gender equality in the school sector and areas which need further improvement.

\section{Materials and Methods}

\section{Sample}

The present research is based on discourse analysis taken from texts and images from three textbooks for secondary school students published in Indonesia in 2014. They are English textbook for grade 8 (T1), grade 10 (T2) and grade 11 (T3). They are textbooks approved by the Indonesian Ministry of Education to be used throughout Indonesia. As this study was intended to describe and investigate the representation or equality of males and females in the textbooks. The data of this study is the researcher took the data in two forms, which were in the form of language items in monolog texts and illustrations "pictures" from the first until the last chapters of each textbook.

\section{Instruments}

In this study, the researchers developed a checklist for collecting and analyzing the data on the existence of gender equality in EFL textbook through the use of language items in monolog texts and in pictures as an instrument through theory triangulation. Language items dimension was developed from nine theories on textbook evaluation related to gender representation. They are including five sub dimensions, namely (1) male and female characters, occupational roles, amount of talk, male and female in domestic roles, and firstness (Cohen \& Manion, 1992; Dominguez, 2003; Stockdale, 2006); (2) male and female characters, occupational roles, amount of talk, and male and female pictures in domestic roles (Cohen \& Manion, 1992; Dominguez, 2003; Chung, 2014; Porreca, 1984); (3) amount of talk refer to the participants male/female who involve dominantly in conversation (Stockdale, 2006; Dominguez, 2003); (4) male and female in domestic roles mentioned in monolog texts, who becomes the actor in social activities, like who earns money or does household activities. (e.g. father, mother, son and daughter) (Cohen and Manion, 1992; Chung, 2014); and (5) firstness refers to who appears in the first position such as she and he or he and she, or mother and father mentioned in monolog text (Porreca, 1984; Stockdale, 2006). Meanwhile, the second dimension is illustration, which consists of four sub dimensions, including (1) Male and Female character's name appear in the pictures (e.g. he, she, Ms., Miss, Mrs., and Mr.) (Chung, 2014; Nofal \& Qawar, 2015); (2) Occupational roles refer to who occupies in certain job or occupation in the picture (e.g doctor, teacher, pianist, etc.) (Gharbavi, 2012; Gjorup, 2006; Nofal \& Qawar, 2015); (3) Amount of talk refers to male or female picture appears dominantly while having conversations (Dominguez, 2003; Stockdale, 2006); and (4) Male and female pictures that do domestic roles (e.g. father, mother, son and daughter) (Gharbavi, 2012; Nofal \& Qawar, 2015). Prior to utilizing the checklist, in order to prepare trustworthiness of the instrument, an expert in textbook analysis, an expert in gender studies, and an expert in English language teaching validate the checklist. 
Method of Analysis

In this present study, researchers utilized manual method of analyzing gender representation by employing content analysis. The content analysis method is widely used in textbook studies allowed researchers to reveal interpretation of gender equality of the textbooks, as it consists of evaluation of the content of a text and provides background for subsequent liguistic analysis (Sunderland, 1994). Accordingly, if the difference in the amount obtained from counting the texts and illustrations from stereotypes of women and men is more than $5 \%$, then it is categorized as a gender bias (Stockdale, 2006).

\section{Results and Discussions}

\section{Language Items}

There were five sub dimensions that described the criteria of language items in monolog texts. They were the male and female characters name, occupational roles refer to who occupies in certain job, amount of talk refer to the participants male/female who dominantly in conversation, male and female in domestic roles and firstness refers to who appears in the first position. The gender equality representation of textbook in terms of language items was found based on the fulfillment of every description in each sub dimension.

The total number of the language items criteria was clearly depicted in Table 1, they are (1) the number of male and female characters name mentioned in monolog texts were 391 for male and 246 for female; (2) the number of occupational roles refer to who occupies in certain job were 11 for male and 6 for female; (3) the number of amount of talk were 301 for male and 262 for female; (4) the number of male and female in domestic roles were 9 for male and 6 for female; and (5) the number of firstness were 56 for male and 34 for female. The data found was calculated by summing up the overall number that appear in the gender of female and male in each sub dimensions, so the researcher got the result of gender representation in the language items of the textbooks. The language items then were drawn by the level of suitability.

Table 1: Language Items Frequency

\begin{tabular}{|c|c|c|c|}
\hline \multirow[t]{2}{*}{ Sub dimension } & \multirow[t]{2}{*}{ Textbook } & \multicolumn{2}{|c|}{ Frequency } \\
\hline & & Female & Male \\
\hline \multirow{3}{*}{$\begin{array}{l}\text { Male and Female character's name mentioned in monolog } \\
\text { text. The pronouns and name show gender like he, his, } \\
\text { him, Mr will be classified in male, while she, her, Ms, } \\
\text { Miss, Mrs will be classified in female category. }\end{array}$} & $\mathrm{T} 1$ & 24 & 67 \\
\hline & $\mathrm{T} 2$ & 127 & 174 \\
\hline & T3 & 95 & 150 \\
\hline \multirow{3}{*}{$\begin{array}{l}\text { Occupational roles refer to who occupies in certain job or } \\
\text { occupation mentioned in monolog text. (e.g doctor, } \\
\text { teacher, pianist, etc.) }\end{array}$} & $\mathrm{T} 1$ & 4 & 4 \\
\hline & $\mathrm{T} 2$ & 1 & 4 \\
\hline & $\mathrm{T} 3$ & 1 & 3 \\
\hline \multirow{3}{*}{$\begin{array}{l}\text { Amount of talk refer to the participants male/female who } \\
\text { involve dominantly in conversation. }\end{array}$} & $\mathrm{T} 1$ & 126 & 168 \\
\hline & $\mathrm{T} 2$ & 70 & 83 \\
\hline & $\mathrm{T} 3$ & 66 & 50 \\
\hline \multirow{3}{*}{$\begin{array}{l}\text { Male and female in domestic roles mentioned in monolog } \\
\text { texts, who becomes the actor in social activities, like who } \\
\text { earns money or does household activities. (e.g. father, } \\
\text { mother, son and daughter) }\end{array}$} & $\mathrm{T} 1$ & 2 & 2 \\
\hline & $\mathrm{T} 2$ & 1 & 3 \\
\hline & $\mathrm{T} 3$ & 3 & 4 \\
\hline
\end{tabular}


Firstness refers to who appears in the first position such as she and he or he and she, or mother and father mentioned in monolog text.

Total

\begin{tabular}{|c|c|c|}
\hline $\mathrm{T} 1$ & 20 & 25 \\
\hline $\mathrm{T} 2$ & 11 & 23 \\
\hline $\mathrm{T} 3$ & 3 & 8 \\
\hline & $\begin{array}{c}\mathbf{5 5 0} \\
\mathbf{( 4 2 \% )}\end{array}$ & $\begin{array}{c}\mathbf{7 6 8} \\
\mathbf{5 8 \%})\end{array}$ \\
\hline
\end{tabular}

Based on results, the level of suitability of the textbooks in terms of appear gender equality in language items were 768 (42\%) male and 550 (58\%) female, and there was $16 \%$ difference, it means that the gender representation in the textbooks in terms of language in monolog texts was imbalance.

\section{Illustrations}

There were four sub dimensions that would be described as the criteria of illustrations in pictures, those were: male and female character's name, occupational roles, amount of talk and male and female pictures in domestic roles. The gender equality representations of textbook in terms of illustrations were found based on the fulfillment of every description in each sub dimensions.

The total number of the illustrations criteria was seen in Table 2, they are (1) the number of male and female characters name appear in the pictures were 391 for male and 246 for female; (2) the number of occupational roles refer to who occupies in certain job were 11 for male and 6 for female; (3) the number of amount of talk were 136 for male and 136 for female; and (4) the number of male and female pictures that do domestic roles were 9 for male and 6 for female. The data found was calculated by summing up the overall number that appear in the gender of male and female in each sub dimensions, so the researcher got the result of gender representation in the illustrations of textbooks. The illustrations then were drawn by the level of suitability.

Table 2: Illustrations

\begin{tabular}{|l|c|c|c|}
\hline Sub dimension & \multirow{2}{*}{ Textbook } & \multicolumn{2}{|c|}{ Frequency } \\
\cline { 2 - 3 } & & Female & Male \\
\hline Male and Female character's name appear in the pictures & $\mathrm{T} 1$ & 24 & 67 \\
\cline { 2 - 4 } (e.g. he, she, Ms., Miss, Mrs., and Mr.) & $\mathrm{T} 2$ & 127 & 174 \\
\cline { 2 - 4 } & $\mathrm{T} 3$ & 95 & 150 \\
\hline $\begin{array}{l}\text { Occupational roles refer to who occupies in certain job or } \\
\text { occupation in the picture (e.g doctor, teacher, pianist, etc.) }\end{array}$ & $\mathrm{T} 1$ & 4 & 4 \\
\cline { 2 - 4 } & $\mathrm{T} 2$ & 1 & 4 \\
\cline { 2 - 4 } & $\mathrm{T} 3$ & 1 & 3 \\
\hline Amount of talk refers to male or female picture appears & $\mathrm{T} 1$ & 126 & 145 \\
\cline { 2 - 4 } dominantly while having conversations. & $\mathrm{T} 2$ & 2 & 1 \\
\cline { 2 - 4 } & $\mathrm{T} 3$ & 8 & 0 \\
\hline Male and female pictures that do domestic roles (e.g. father, \\
mother, son and daughter). & $\mathrm{T} 1$ & 2 & 2 \\
\cline { 2 - 4 } & $\mathrm{T} 2$ & $\mathbf{3}$ & $\mathbf{4}$ \\
\cline { 2 - 4 } & $\mathrm{T} 3$ & $\mathbf{3 9 4}$ & $\mathbf{5 5 7}$ \\
\hline Total & & $\mathbf{( 4 1 \% )}$ & $\mathbf{( 5 9 \% )}$ \\
\hline
\end{tabular}

Based on results, the level of suitability of textbook in terms of appear gender equality in illustrations were 557(41\%) male and 394 (59\%) female, and there was $18 \%$ differences. 
Accordingly, it means that the gender representation in the textbooks in terms of appear language items was imbalance.

Gender representation in the textbooks for the first year students has been evaluated by the researchers using textbook evaluation checklist. This analysis was divided into two dimensions; language items in monolog texts and illustrations in pictures. These two criteria are considered imbalance. Since the results of this research was imbalance in each sub dimensions between male and female in gender equality representation, the researcher assumes that the result can be influenced by some reasons. Asian culture and the country development level may affect the imbalance. The first reason is Asian culture; especially traditional belief such as "female as caregivers and male as breadwinners" is still hold thigh by the Asian people. Stockdale (2006) found that females are still primary caregivers for children and more responsible for the domestic roles, while male as breadwinners can be seen in occupational sub dimension. It showed that male dominantly in relation of the workplace rather than female.

The second reason is for the imbalance of gender equality representation in this textbook is the country development level. Most of the people in developing countries still believe that "male as breadwinners" and "female as housewives". For example, is in Indonesia as the setting of this research, many people assume that female is appropriate to work at home or in institution. On the other hand, in developing countries i.e. Indonesia have proven to be far behind with developed countries that have a level of gender equality in terms of employment, for example is Japan as a developed country. The majority of female in Japan choose to be female carrier rather than a housewife. Nagatomo (2010) in her research mentions that female had visual majority by appearing in $62 \%$ of the illustrations that included people. The majority of the characters speaking in conversations and task listening exercises were female, which spoke first $65 \%$ of the time in conversations and $40 \%$ of the time in the task exercises. The result implies that female characters in Japan were more visible and played more active roles than male characters. Since this textbook from Indonesia, so the females become subordinate gender occupying in certain job.

Gender Representation in the textbooks for the first year students is considered as imbalance, so the textbook has strengths and weaknesses. The first strength is the textbook is colorful and the language instruction or language use is clearly and make students easier to understand. According to Brown (2007) the richness of language instruction is important to support material. The second strength is that the textbook is good in providing clear pictures and prints which can support students in using this textbook. Based on Lawrence (2011) the clarity of pictures can enhance the degree of visual support. The third strength is the textbook provides good examples of type texts which can help students to relate it with their daily life. It fulfilled a criterion which is suggested by Lawrence (2011) that reading material or activities should help students to relate English language learning to daily life.

\section{Conclusions \& Recommendations}

Based on the research findings, the researcher concluded that this research has answered the problem of the study. The conclusion was gender representation the textbooks for the first year students in terms of language items in monolog texts was 768 male and 550 female and illustrations in pictures was 557 male and 394 female. In the overall number for gender equality representation 
of textbook in terms of those two criteria dimensions was appear to be imbalance as a component in designing and implementing a classroom lesson. The Asian culture and the development level of the country may affect the imbalance. Therefore, the English teacher is highly recommended to adapt or adopt other additional textbooks from various resources to obtain the gender equality goal.

This research can be used by English teachers to determine whether they want to use the textbooks for the first year students or not by knowing the information served in the findings of this research. They may know which aspect of this textbook should be revised or changed in order to get the best of textbook use. English teachers should do some improvement especially for gender equality representation to get the best use of textbook. The teacher may make their own dialogues to be additional materials in order to gain gender equality representation using conversations.

Future researchers may conduct the same research of textbook evaluation using the gender equality representation textbook evaluation checklist. The checklist can be adapted or modified by the future researchers. For better analysis, the researcher suggests to the future researchers to conduct interview to English teacher to get supporting data from who were using the textbook.

\section{Acknowledgements}

The authors would like to express their appreciation for the support of the sponsors with Institute of Research and Community Services (LPMM) Universitas Brawijaya for Hibah Penelitian Pemula No. DIPA-042.01.2.400919/2019.

\section{References}

[1] Al-Qatawneh, S. \& Al-Rawashdeh, A. (2019). Gender Representation in the Arabic Language Textbook for the Ninth Grade Approved by the Ministry of Education for Use in Schools in the United Arab Emirates (UAE). Studies in Educational Evaluation 60: 90-98.

[2] Kochuthara, S.G. (2011). Patriarchy and Sexual Roles: Active-passive Gender Roles Versus an Ethics of Mutuality. Journal of Dharma, 36 (4): 435-452.

[3] Lee, J.F.K. (2014). A Hidden Curriculum in Japanese EFL Textbooks: Gender Representation. Linguistics and Education 27: 39-53.

[4] Gebregeorgis, M. Y. (2016). Gender Construction through Textbooks: the Case of an Ethiopian Primary English Textbook. Africa Education Review, 13 (3-4): 119-140.

[5] Yang, C.C.R. (2011). Gender Representation in a Hong Kong Primary English Textbook Series: the Relationship between Language Planning and Social Policy. Current Issues in Language Planning 12 (1): 77-88.

[6] Barton, A. \& Sakwa, L.N. (2012). The Representation of Gender in English Textbooks in Uganda. Pedagogy, Culture \& Society 20 (2): 173-190.

[7] Apple, M.W. (2004). Ideology and Curriculum. New York: Routledge.

[8] Chu, Y. (2018). Visualizing Minority: Images of Ethnic Minority Groups in Chinese Elementary Social Studies Textbooks. The Journal of Social Studies Research 42: 135-147.

[9] Eisner, E. W. (2002). The Educational Imagination. Columbus: Prentice Hall.

[10] Porecca, K.L. (1984). Sexism in Current ESL Textbooks. TESOL Quarterly, 18 (4): 705-724.

[11] Mineshima, M. (2008). Gender Representation in an EFL Textbook. Bulletin of Nigata Institute of Technology, 13: 121-140.

[12] Elmiana, D.S. (2019). Pedagogical representation of visualimages in EFL textbooks: a multimodal perspective, Pedagogy, Culture \& Society,pp. 1-16 
[13] Sunderland, J. (1994). Exploring gender: Questions and implications for English language education. New York, NY: Prentice Hall.

[14] Cohen, L . \& L. Manion. (1992). Research method in education ( $3^{\text {rd }}$ ed.): London: Rutledge.

[15] Chung, H. C. P. (2014). Textbooks and genders : gender representation in teaching materials of liberal studies in Hong Kong. (Thesis). University of Hong Kong, Pokfulam, Hong Kong SAR.

[16] Dominguez, M.L. (2003). Gender textbook evaluation. Paper for English Language Studies Department of English University of Birmingham.

[17] Gharbavi, A. \& Mousavi, S.A. (2012). A content analysis of textbooks: investigating gender biased as a social prominence in iranian high school english textbook. English Linguistics Research 1(1), pp. 42-49.

[18] Gjorup, P.H.L (2006). The representation of gender and gender roles in english textbooks. (Dissertation). Malmö University.

[19] Nofal, M.Y. and Qawar, H.A. (2015). Gender representation in english language textbooks: action park 10. American Journal of Educational Science 1(2), pp. 14-18

[20] Porreca, K.L. (1984). Sexism in Current ESL.TESOL Quarterly 18 (4):705-724.

[21] Stockdale, D. A (2006). Gender representation in an efl textbook. Paper submitted to the School of Humanities of the University of Birmingham, UK

[22] Nagatomo, (2010). A Critical analysis of gender representation in an efl textbook: Ochanomizu University.

[23] Lawrance, W. P. W. (2011). Textbook evaluation: a framework for evaluating the fitness of the hong kong new secondary school (nss) curriculum. Published Dissertation. Hong Kong: Department of English City University of Hong Kong

*Corresponding author.

E-mail address: ive@ ac.id/arcci_tusita@ ub.ac.id 